\title{
Historical perspectives of The American Association for Thoracic Surgery: Herbert C. Maier (1908-1993)
}

\author{
Abe DeAnda, Jr, MD, and Leora B. Balsam, MD
}

Herbert Caillé Maier, 46th president of The American Association for Thoracic Surgery, was born on March 24, 1908, the son of Otto and Dina Maier. Dr Otto Maier was a successful generalist in Manhattan, and both he and Dina had emigrated from Germany at the end of the 19th century. They started their family late in life; their daughter Dorothea was born in 1906, when both parents were 41, and Herbert was born a year later. At the age of 12, Herbert had diabetes insipidus, which was a poorly understood disease in 1920 . His case was so severe that he was forced to take a 5-month leave of absence from Trinity school in New York City. Maier's initial polydipsia and polyuria gradually resolved, and he was able to go back to school, with his only symptom being occasional headaches. Eventually, he matriculated as an undergraduate at Columbia University, where he received his AB in 1928. After graduation, he enrolled in medical school at Columbia University. He graduated in 1932 and stayed on as a resident in surgery.

In 1938, Maier's headaches became more frequent and severe, at times affecting his ability to perform as a resident surgeon. Maier described his symptoms as "a pounding pulsation concomitant with each heartbeat which developed in the head and upper neck after climbing a flight or two of stairs." "When these episodes occurred, he was nearly incapacitated by the pain. Skull radiographs revealed bone destruction of the dorsum sellae and a tumor mass of the left maxillary sinus. After radiation therapy for presumed craniopharyngioma, his symptoms resolved; however, the radiation therapy was not without consequence. Maier described the development of impaired immunity, manifested by frequent infections, and pituitary deficiency requiring lifelong cortisone and thyroid replacement therapy.

With his symptoms controlled, Maier was able to return to his clinical activities. After completion of his surgical training and a period of postdoctoral study at the University of Michigan (where he received the designation "MedScD," a distinction he included in all his correspondence), he became an instructor and eventually Clinical Professor of

\footnotetext{
From the Department of Cardiothoracic Surgery, New York University-Langone Medical Center, New York, NY.

Disclosures: Authors have nothing to disclose with regard to commercial support.

Received for publication July 30, 2012; accepted for publication Sept 13, 2012; available ahead of print Oct 5, 2012.

Address for reprints: Abe DeAnda, MD, Department of Cardiothoracic Surgery

NYU-Langone Medical Center, 530 First Ave, Suite 9V, New York, NY 10016

(E-mail: abe.deanda@nyumc.org).

J Thorac Cardiovasc Surg 2012;144:1283-4

$0022-5223 / \$ 36.00$

Copyright (C) 2012 by The American Association for Thoracic Surgery

http://dx.doi.org/10.1016/j.jtcvs.2012.09.024
}

Surgery at Columbia-Presbyterian and New York University. His clinical practice initially was at Bellevue Hospital Center and subsequently Lenox Hill Hospital, where he spent the remainder of his career.

Dr Maier was an inaugural member of the International Surgical Group, founded in 1958 by surgical leaders from the United Kingdom, Scandinavia, Canada, and the United States who wished to rekindle professional relationships established during World War II (Figure 1). The idea was to create a small group of distinguished and scientifically minded transatlantic academic and clinical surgeons who would meet on a regular basis for an exchange of experiences and ideas. Intimacy was a key ingredient of this meeting; surgeons were encouraged to address each other only on a first-name basis. The small size of the meeting, the intimacy and close personal relationships of the participants, and the emphasis on scholarship all meshed with Maier's personality. It is notable that, of Maier's 61 indexed journal articles, he was the sole author of 35 , almost $60 \%$. He was most comfortable working alone. Maier's son, Donald B. Maier, MD (personal correspondence, July, 2012) summarized his father's tendency toward introversion, "He didn't have many people skills. I think he was proud of what he did but didn't know how to talk to others about it."

Twenty-four years after his initial radiotherapy, a new symptom appeared; drainage of yellowish fluid from Maier's mouth, initially during sleep and occasionally tinged with blood. Maier was chair of the American Board of Thoracic Surgery at the time (1961-1963). The drainage was occasionally rancid and associated with painful headaches and paroxysmal coughing attacks. The attacks became more virulent and affected his professional duties, culminating in an epileptiform seizure violent enough to result in a right shoulder dislocation. The decision was made to proceed with a second course of radiotherapy (4100 rad in addition to the original 2400-rad dose), but he became debilitated by the drainage and pain. At the age of 56, he stepped down as Chief of Thoracic Surgery at Lenox Hill. He continued to practice, but at a reduced level, until age 65. Despite this incredible personal challenge and medical setback, Maier's academic colleagues continued to support him and promote his rise in leadership at the national level.

On May 16, 1966, 2 years after stepping down as the chief, Dr Maier presented his presidential address at The American Association for Thoracic Surgery annual meeting in Vancouver. Maier had distinguished himself as an authority in thoracic anatomy and physiology, and his address "The Pulmonary and Pleural Lymphatics: A Challenge to the Thoracic Explorer,"2 illustrated both his 


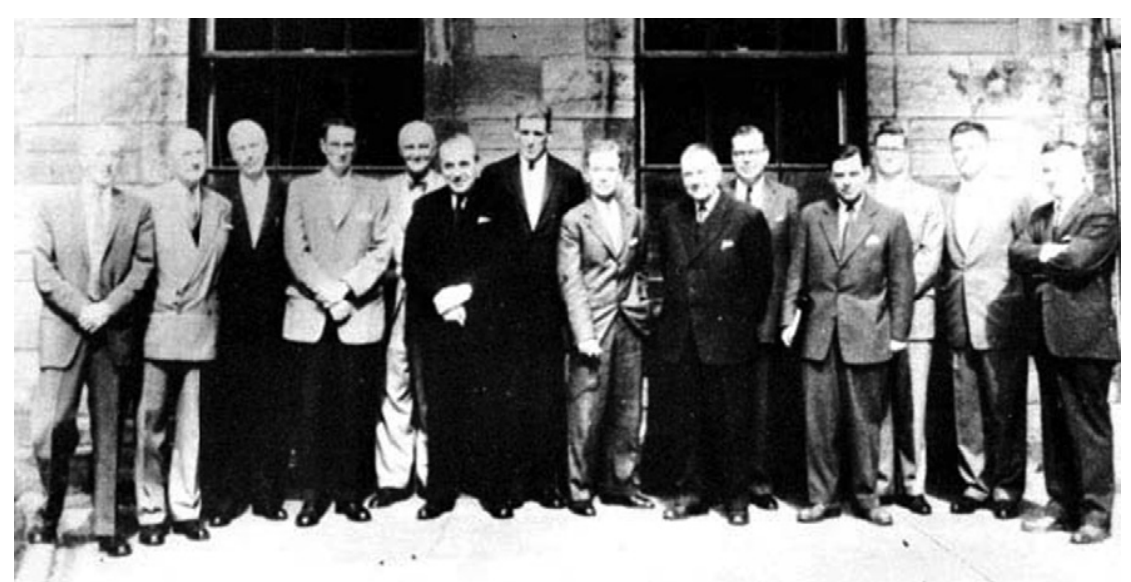

FIGURE 1. Inaugural meeting in Edinburgh of the International Surgical Group, July 17, 1958. Left to right: Gordon Murray, Charles Wells, Philip Sandblom, Henry Harkins, John Gibbon (41st American Association for Thoracic Surgery president), John Bruce, Jonathan Rhoads, Ian Aird, Erling DahlIversen, Herbert Maier, Eiven Hasner, James Hardy, Jerome Urban, and William Glenn.

expertise and interest. Maier concluded by challenging the audience to continue the quest to correlate basic science research with clinical problems, stating, "When the thoracic explorers of the future...have conquered the problem of pulmonary edema and other fluid aberrations in the lungs,

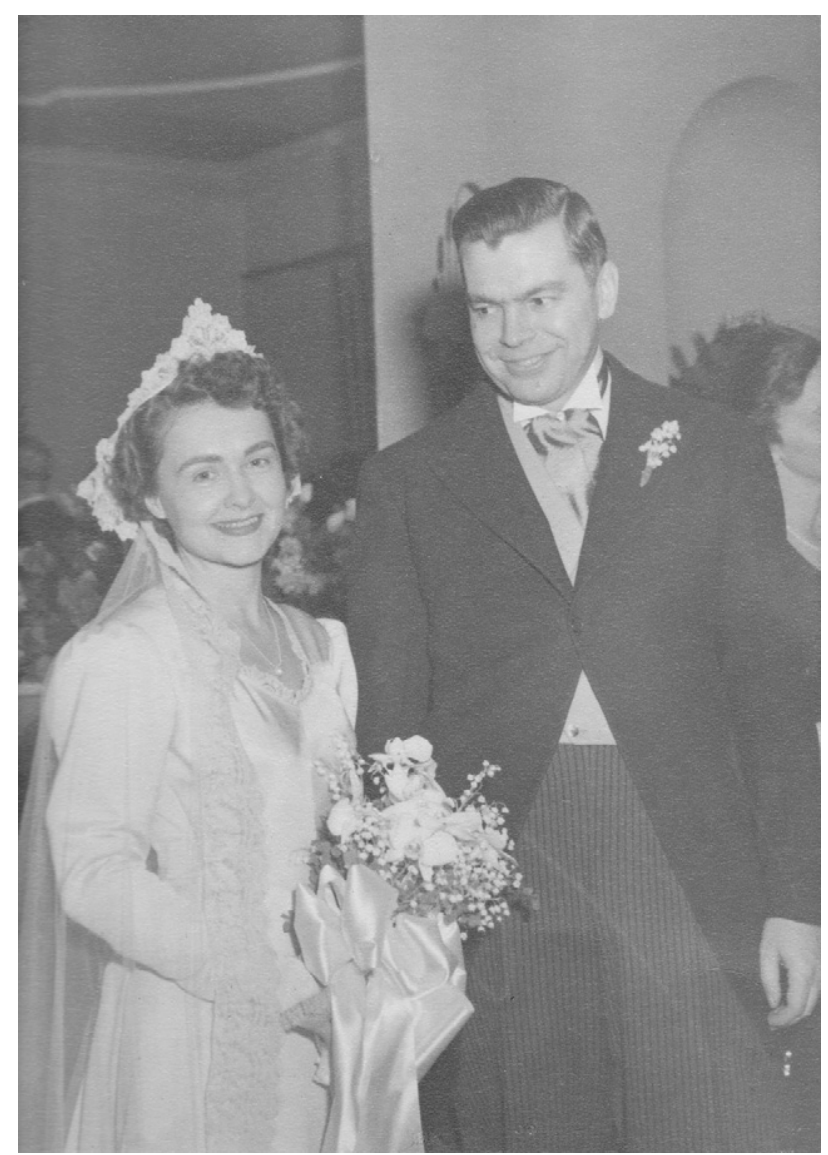

FIGURE 2. Wedding photo of Drs Herbert C. Maier and Janet Baldwin. Dr Baldwin, a graduate of Johns Hopkins School of Medicine, was a noted pediatric cardiologist. and have given the pulmonary and pleural lymphatics the attention this vital system merits, a significant reduction in the morbidity and mortality of thoracic disease will be attained." 2 Maier's attention to detail was recognized and admired by colleagues and others. Noted historian Andreas Naef from Switzerland summarized that Maier "impressed me very much, not by his operations but by his encyclopedic culture in thoracic pathology, radiology, and diagnosis in general.", 3

By the age of 72, Maier had become severely disabled from a steroid myopathy and was dependent on Demerol for treatment of chronic pain. He died September 1, 1993, in Avon, Connecticut at the age of 85, preceded in death by both his first wife, Janet Baldwin (Figure 2), and his second wife, Hilde Maier née Collison. Despite his many accomplishments and credits, Herbert Maier left few accessible monuments to his life and works. As related by his son (personal correspondence, July, 2012), "My father's life centered on medicine. He had few personal contacts beyond his medical colleagues. He was not one to socialize, and generally kept to himself." Nevertheless, Herbert Maier's contributions to the understanding of thoracic anatomy and the interaction of anatomy with pathology should not be forgotten.

We acknowledge and thank Donald B. Maier, MD, for providing insightful comments and information about his father. We also thank Dimitri A. Raptis, MD, and Pierre-Alain Clavien, MD, PhD, for providing photographs and information regarding the International Surgical Group.

\section{References}

1. Maier HC. Craniopharyngioma with erosion and drainage into the nasopharynx. An autobiographical case report. J Neurosurg. 1985;62:132-4.

2. Maier HC. The pulmonary and pleural lymphatics: a challenge to the thoracic explorer. J Thorac Cardiovasc Surg. 1996;52:155-63.

3. Naef AP. The mid-century revolution in thoracic and cardiovascular surgery: part 2: Prelude to 20th century cardio-thoracic surgery. Interact Cardiovasc Thorac Surg. 2003;2:431-49. 